\title{
O PAPEL DO COORDENADOR PEDAGÓGICO NO CONTEXTO ESCOLAR E SUAS CONTRIBUIÇÕES À PRÁTICA DOCENTE
}

\author{
http://dx.doi.org/10.5902/2318133836808
}

\author{
Eliene Farias Silva ${ }^{1}$
}

\begin{abstract}
Resumo
Neste texto discute-se o papel do coordenador pedagógico no contexto escolar e de que maneira esse profissional contribui para a prática dos docentes. Foi utilizado o levantamento bibliográfico e realizada uma discussão teórica de cunho qualitativo por meio da exploração e confronto de teorias de pesquisadores dedicados no estudo acerca da gestão escolar, especialmente, da coordenação pedagógica. Concluiu-se que a função precípua do coordenador pedagógico é a de auxiliar os professores em sua didática, promovendo-lhes uma reflexão acerca de sua prática. Além disso, esse profissional deve oferecer aos professores momentos de formação continuada para que possam construir uma aprendizagem mútua e trabalhar os desafios apresentados no contexto escolar.

Palavras-chave: coordenador pedagógico; escolar; prática docente.
\end{abstract}

\section{THE ROLE OF THE PEDAGOGICAL COORDINATOR IN THE SCHOOL CONTEXT AND ITS CONTRIBUTIONS TO TEACHER PRACTICE}

\begin{abstract}
This research discusses the role of the pedagogical coordinator in the school context and in what way this professional contributes to the teachers' practice. In the methodology, a bibliographical survey was used, and a theoretical discussion of qualitative character was carried out through the exploration and comparison of the theories of researchers dedicated to the study about school management, especially pedagogical coordination. It was concluded in this study that the primary function of the pedagogical coordinator is to help teachers in their didactics, promoting a reflection on their practice. In addition, this education professional should provide teachers with opportunities for ongoing training so that they can build mutual learning and address the challenges presented in the school context.

Key-words: pedagogical coordinator; school; teaching practice.
\end{abstract}

1 Universidade Estadual de Alagoas, Brasil. E-mail: elienefarias@hotmail.com.

\begin{tabular}{l|l|l|l|l|r|} 
Regae: Rev. Gest. Aval. Educ. & Santa Maria & v. 8 & n. 17 & Pub. contínua 2019 & p. 1-10
\end{tabular}




\section{Introdução}

$\mathrm{N}$ este texto busca-se demonstrar o papel do coordenador pedagógico no contexto escolar e de que maneira esse profissional da educação contribui com à prática docente.

Quem atua na coordenação pedagógica é um professor que, diferentemente dos demais, assume diversas responsabilidades, dentre as quais destaca-se a atribuição de supervisionar, assessorar, acompanhar seus companheiros de profissão, avaliar as atividades pedagógicas e curriculares bem como acompanhar o desenvolvimento dos processos escolares e educativos. Essa é a razão pela qual o coordenador deve se responsabilizar com o trabalho e com a equipe pedagógica de sua escola. Vale ressaltar, que a função desse profissional não está nos limites da escola, ele também desempenha seu trabalho na administração e nas políticas públicas educacionais.

Contudo, a função por excelência que compete ao coordenador pedagógico é a de assistir pedagógico e didaticamente aos professores em suas respectivas disciplinas, em especial no que tange ao trabalho em sala de aula com seus alunos.

Nesse contexto, vê-se que a coordenação escolar é fundamental no desenvolvimento da escola e no êxito da mesma. O coordenador pedagógico tem também o dever de mediar a prática dos professores e dos alunos, além de poder intervir nos conflitos existentes que surgem no cotidiano da escola e buscar alternativas para trazer as melhorias necessárias.

Desse modo, objetivamos discutir o papel do coordenador no contexto escolar e sua contribuição à prática docente. Para tanto, o trabalho foi estruturado em três tópicos: no primeiro tópico foi feita uma contextualização acerca da história da coordenação pedagógica; no segundo tópico foram abordadas algumas definições de coordenador pedagógico, sua formação e o que ele significa para o ambiente escolar e, por fim, foi abordado as atribuições do coordenador escolar e as contribuições que ele proporciona à prática docente.

A metodologia empregada neste trabalho é de ordem bibliográfica, ao passo que foi realizada uma discussão teórica de cunho qualitativo por meio da exploração e confronto de teorias de pesquisadores que se dedicaram na temática abordada.

\section{Um breve histórico da coordenação pedagógica no Brasil: da supervisão escolar ao coordenador pedagógico}

Para se entender com precisão a significação da coordenação pedagógica na educação brasileira é importante que se faça um percurso histórico da supervisão escolar e sua transição para a coordenação pedagógica. Diante disso julgamos necessário fazer uma abordagem histórica acerca das transformações pelas quais a supervisão ou orientação escolar passou até chegar no que conhecemos como coordenação pedagógica. Segundo Oliveira (2010),

a supervisão escolar percorreu uma longa trajetória histórica, desde a formalização do ensino e a institucionalização da escola. É importante analisar neste contexto a importância do papel e da função do coordenador a partir dos pressupostos da racionalidade técnica ou da racionalidade emancipatória e os caminhos percorridos por esse papel e essa função em busca de sua materialidade no desenvolvimento das práticas educativas que se desenvolvem na escola. (p. 10) 
Oliveira (2010) afirma que ao investigar a organização das atividades educativas no Brasil, constatou que a ideia de supervisão é muita antiga, pois nasceu por volta dos anos 1600 , especificamente no período do Brasil colonial com jesuítas. A referida autora afirma que a partir dos jesuítas, especificamente com o padre Manuel da Nóbrega, tem-se a formulação do plano de ensino no Brasil, denominado de Ratio Studiorum, que era o plano e organização de estudos da Companhia de Jesus, esse plano de ensino já trazia a ideia de supervisão, consoante o pensamento de Oliveira (2010).

O Ratio Studiorum é um documento voltado especificamente para os propósitos da Ordem dos Jesuítas ou Companhia de Jesus, como também ficou conhecida. Essa ordem foi fundada em 1534 pelo militar espanhol Santo Inácio de Loyola, cujos integrantes são padres com a finalidade de propagar a fé e a doutrina católicas, cumprindo o papel de catequizar as populações (Pinto, 2006). Após o falecimento do padre Nóbrega, o Ratio Studiorum é o documento mais original a estabelecer e conferir um caráter institucional a ideiar a concepção de supervisão. Esse plano de ensino é formado por uma reunião de prescrições que buscam determinar todas as atividades das pessoas que estão relacionadas com o ensino, instituindo, dessa forma, a supervisão pedagógica (Oliveira, 2010).

Nesse contexto é a partir desse conjunto de regras que a função supervisora é posta em ênfase dos demais cargos educativos e, somente com as aulas régias - que foram a primeira sistematização do ensino público, uma vez que a educação estava sob o controle da igreja, especialmente dos jesuítas -, que essa função perde seu prestígio já que a supervisão passou a ser pouco notada após o surgimento da função do diretor geral (Oliveira, 2010).

Em 1920, com a criação da Associação Brasileira de Educação, os profissionais da Educação dão sentido ao surgimento dos técnicos em escolarização e, em 1924, esse plano adquire força e configuração. Diante disso, inúmeros acontecimentos contribuíram para a formação da natureza da supervisão escolar como uma maneira de desenvolver a organização da escola. Pode-se destacar o parecer n. 252/69 em que "se extraem os requisitos básicos para se conferir à supervisão escolar o status de profissão, ou seja, a caracterização da sua necessidade social" (Oliveira, 2010, p. 42). Foi com o parecer 252/69, que os cursos de pedagogia foram reformulados e passaram a ter quatro habilitações, quais sejam: Administração, Inspeção, Supervisão e Orientação.

A coordenação pedagógica, por sua vez, surgiu como uma função no Brasil, no ano de 1920, cuja tarefa tenciona conferir a mesma natureza as propostas e as práticas pedagógicas. Essa função surge em 1961, no Estado de Guanabara, nomeada a princípio de coordenador distrital, mais tarde, em 1965, passou a se chamar de orientador pedagógico (Gomes, 2016).

Durante esse tempo, esse profissional desenvolvia atividades em várias instituições de ensino, somente em 1969, ele passa a atuar em uma única escola. Assistindo os professores do ensino primário, instruindo-os no emprego de "planos e programas elaborados pelos serviços técnicos e dos métodos por eles sugeridos, sem prejudicar a autonomia do professor, respeitando os princípios básicos da educação" (Gomes, 2016, p. 13). 
Nesse período, a função precípua do coordenador, era a de controlar o emprego dos métodos que tornassem o ensino e a aprendizagem dos alunos completa, ou seja, sem nenhum defeito (Gomes, 2016).

Para Oliveira (2016), o profissional incumbido de atuar na coordenação pedagógica possui uma tarefa delicada, porque muitas vezes, algumas situações que surgem no âmbito escolar, estão além da formação que ele recebeu durante sua vida acadêmica.

Mesmo tendo ciência dos obstáculos de desenvolver um trabalho que tenha um sentido para o contexto escolar, o coordenador pedagógico deve atuar com a certeza de que seu trabalho na coordenação pedagógica tem um papel relevante tanto no processo de ensino e aprendizagem como na transformação educacional (Oliveira, 2016).

Ainda de acordo com as observações de Oliveira (2016), em sua monografia de especialização em Coordenação pedagógica, "O papel do coordenador pedagógico na mediação das novas tecnologias na prática pedagógica", o desenvolvimento do fazer pedagógico do professor está intimamente relacionado ao trabalho do coordenador. Oliveira e Guimarães (2013) destacam que

na formação docente é muito importante prestar atenção no outro, em seus saberes, difculdades, sabendo reconhecer e conhecer essas necessidades, propiciando subsídios necessários; assim a relação entre professores e coordenadores à medida que se estreita, crescem em sentido prático e teórico. (p. 98)

Isso justifica a relevância desse profissional da educação no "ambiente escolar, coordenando os trabalhos escolares, e assim, contribuindo para a melhoria do lidar pedagógico em sala de aula e fora dela, mas inserido no ambiente escolar" (Oliveira, 2016, p. 23).

\section{Coordenador pedagógico: definições, formação e significados}

De acordo com Silva ([s/a], p. 39706) o coordenador pedagógico é profissional "que coordenará o trabalho realizado na escola de forma que este não se torne individualista, alienado e desarticulado com a realidade e a necessidade do professor e do aluno"

No dicionário de Aurélio Buarque de Holanda Ferreira (2001, p. 196), o vocábulo coordenar recebe três definições. Na primeira, coordenar significa: "dispor segundo certa ordem e método". Na segunda definição, coordenar é conceituada como "organizar e/ou dirigir, dando orientação". Por fim, na terceira e última definição, Holanda (2001) ainda afirma que coordenar é também conceituado como "ligar-se coerentemente".

O coordenador pedagógico é, antes de tudo, um professor que, de modo diferente dos demais professores, deve responder pelas obrigações que lhe foram confiadas, a saber: "a operacionalização do acompanhamento de seus companheiros de profissão, dos índices da escola e do desenvolvimento dos processos escolares como um todo" (Leite; Miranda; Veras, 2017, p. 31).

O processo de formação desse professor habilitado para o exercício de atuar na gestão escolar, mas especificamente na coordenação pedagógica, é contemplado na LDB, no artigo 64: 
A formação de profissionais de educação para administração, planejamento, inspeção, supervisão e orientação educacional para a educação básica, será feita em cursos de graduação em pedagogia ou em nível de pós-graduação, a critério da instituição de ensino, garantida, nesta formação, a base comum nacional.

Oliveira e Guimarães (2013) tecem comentários sobre a formação dos profissionais habilitados à coordenação pedagógica, cuja discussão perpassa pela formação inicial e continuada desses profissionais. Assim, elas destacam que a

formação requisitada para o exercício da função de coordenador não pode se resumir em um acúmulo de títulos, precisa ser um processo reflexivo e crítico sobre a prática pedagógica. Os cursos de Pedagogia precisam investir na formação do coordenador, pois se trata de uma função essencial e complexa no campo educativo e que não dá para aprender somente com a prática, é preciso desenvolver capacidades e habilidades múltiplas em consonância com a educação atual. A formação continuada do coordenador pedagógico faz-se necessária pela própria natureza do saber humano como prática que se transforma constantemente, principalmente quando se refere ao comportamento e seus efeitos na aprendizagem. (p. 97)

Sendo assim, uma das funções que o coordenador pedagógico deve exercer no contexto escolar é a de articular e mediar a formação continuada dos docentes que estão sob a sua responsabilidade, procurando opções para conciliar tarefas de apoio e formação de professores, levando em consideração as novas necessidades educacionais (Oliveira; Guimarães, 2013).

A formação continuada deve ser uma constante na vida de todos os profissionais, especialmente dos que integram o quadro da educação. Dessa forma, a formação continuada não pode ser, de modo algum, dispensada pelo coordenador, uma vez que para o mesmo ter êxito durante o período em que estiver na gestão escolar, ela se faz necessária, porque

são os conhecimentos adquiridos nos cursos de formação continuada que ajudarão o coordenador a entender e orientar seus professores de forma satisfatória, aproveitando a experiência anterior e fazendo uma nova prática a partir dos conhecimentos adquiridos [...] A educação continuada do coordenador pedagógico, para ter realmente sucesso dentro do contexto escolar, deve ter como objetivo central a reflexão sobre a prática, tendo em vista uma reconstrução da autonomia intelectual não só para si, mas para toda equipe escolar. (Oliveira; Guimarães, 2013, p. 97)

Pelo exposto, pode-se inferir que coordenar o trabalho pedagógico não é uma tarefa fácil visto que se exige do coordenador competências diversificadas e posicionamentos múltiplos, como pessoais, administrativos, políticos e pedagógicos (Oliveira; Guimarães 2013).

Diante disso, é importante que os cursos de Pedagogia formem profissionais com autonomia intelectual, que sejam sujeitos críticos e reflexivos no que diz respeito à prática pedagógica e, sobretudo, que tenham ciência de sua função na escola, tendo em vista 
que o ambiente escolar é um espaço vivo e dinâmico. Logo exige-se que os profissionais sejam capazes de reinventar-se de acordo com as especificidades de cada situação vivenciada no cotidiano da escola.

Por esse motivo é que são múltiplas as funções do professor-coordenador, tendo em vista a dinamicidade da escola, conforme o pensamento de Silva (2015) quando faz abordagens acerca do papel do coordenador pedagógico e a possibilidade que este profissional tem de atuar na formação do professor:

A dinâmica do trabalho pedagógico na escola é bastante ágil e diversa, os tempos e horários pré-determinados e padrões dificultam as interações entre os professores e o planejamento coletivo. Assim o espaço da coordenação pedagógica e o papel do coordenador pedagógico continuam essenciais para realizar essa articulação necessária entre os profissionais da escola, principalmente em relação à formação continuada que faz parte de suas das atribuições. (Silva, 2015, p. 180)

Por essa razão, o trabalho do coordenador é considerado árduo, pois ele "enfrenta o desafio de construir seu novo perfil profissional e delimitar seu espaço de atuação, porém precisa resgatar sua identidade e consolidar um trabalho que vai muito além da dimensão pedagógica" (Oliveira; Guimarães, 2013, p. 96).

Desse modo, o coordenador pedagógico é o profissional que trabalha com a equipe de docentes, especialmente com a formação desses profissionais da educação. Ele deve ter habilidade nas diversas didáticas e ser mais experiente que os professores que estão em sala de aula, já que ele deve dá o suporte necessário aos desafios existentes no contexto educacional, ou seja, na escola. Nesse sentido,

o coordenador pedagógico precisa compreender sua função na escola e deve se trabalhar lado a lado com os professores a fim de que contribua no processo educativo, promovendo a reflexão da prática docente, assumindo um compromisso de junto ao professor trabalhar as dificuldades apresentadas no contexto escolar. (Farias; Farias; Silva; Magalhães; 2017, p. 2)

Além disso, o coordenador, deve desenvolver seu trabalho juntamente com o diretor escolar para que, por meio dessa relação de parceria, possam transformar a escola em um espaço de aprendizagem.

É interessante destacar que só se obtêm êxito quando o trabalho do coordenador é fundamentado no diálogo, no trabalho em equipe, já que a participação de todos é necessária e basilar para a promoção de metodologias que proporcionem saberes e fazeres escolares significativos. Tudo isso, aliás, está em conformidade com as observações de Gomes (2016), quando acentua as atribuições conferidas ao coordenador pedagógico e sua importância para o contexto escolar:

Percebe-se, portanto, que o coordenador pedagógico é aquele profissional que tem por atribuição no âmbito escolar, articular, coordenar, acompanhar, supervisionar, orientar o desempenho do trabalho pedagógico que se desenvolve no interior da escola, na perspectiva da realização de um espaço escolar que propicie o desenvolvimento da aprendizagem, nos conhecimentos dos valores da cidadania, fortalecendo o ensino. (p. 16) 
À vista disso, pode-se perceber que o coordenador pedagógico precisa oferecer subsídio aos professores para que estes possam compreender "melhor sua prática e dificuldades encontradas no dia a dia escolar, além de ser um forte articulador na educação continuada dos mesmos" (Farias; Farias; Silva; Magalhães; 2017, p. 3).

Nesse contexto, ao tornar possível a articulação de conhecimentos, o coordenador pedagógico abre novas perspectivas e caminhos para que os professores reflitam acerca de suas ações e, consequentemente, que olhem com minuciosidade para o contexto educacional no qual estão inseridos.

A abundância de significados conferidos a esse profissional da educação, como visto acima, revela que o coordenador pedagógico é um profissional com distintas atribuições, dentre as quais pode-se destacar sua responsabilidade na integração com os alunos, com os professores e com os demais que constituem o ambiente escolar (Gomes, 2016).

\section{Coordenador pedagógico: das atribuições às contribuições à prática docente}

Inúmeras são as atribuições conferidas ao coordenador pedagógico. No entanto, descrever e tentar explicar cada uma delas, seria um trabalho quase infindável. Por essa razão, neste tópico, serão destacadas as atribuições que são consideradas por nós, e principalmente pelos teóricos como essenciais.

Cabe ao coordenador pedagógico ter conhecimento de suas funções, de seus direitos e de seus deveres. Gomes (2016) ressalta as multifacetadas funções do professor-coordenador:

Os coordenadores executam uma grande variedade de tarefas, que podem ou não incluir funções administrativas. O coordenador deve ser cumpridor das funções de coordenação, consultor, líder do grupo e avaliador dentro dos domínios do desenvolvimento instrucional, curricular e pessoal. Os coordenadores devem possuir uma mistura sensata de técnicas e gerências e habilidades relações humanas. Liderança e habilidades de comunicação interpessoal parecem ser especialmente importantes para a coordenação de sucesso. O coordenador deve possuir tais características, pois irão permitir-Ihe trabalhar de forma harmoniosa com os demais, além de adquirir conhecimentos e habilidades suficientes para executar todas as funções de forma eficaz. (p. 18)

O trabalho do coordenador pedagógico no âmbito escolar é vasto e intensamente delicado. Muitas vezes, ele não percebe a complexidade da responsabilidade que the foi outorgada, talvez isso aconteça pela formação acadêmica não ter sido satisfatória ou pela ausência de uma formação continuada, consoante o raciocínio de Oliveira e Guimarães (2013).

Conforme as observações de Gomes (2016, p. 18) a primeira função do coordenador pedagógico é planejar e acompanhar a efetivação das atividades didáticopedagógicas da escola. Essa tarefa é de suma importância e de incontestável responsabilidade, uma vez que limita todas as possibilidades como também os limites da ação de atuar desse profissional.

Nas palavras de Oliveira (2018, p.23), pode ser contemplado os elementos basilares para que a escola se torne um espaço de aprendizagem significativa e, como será visto, a principal figura nesse processo é a coordenação pedagógica, na pessoa do coordenador: 
Os papéis de todos de todos os envolvidos no processo educativo são essenciais para a melhoria da escola de hoje. A função da gestão escolar, professores, e principalmente do coordenador pedagógico elemento essencial nesse processo educativo (OLIVEIRA, 2018, p.23).

De acordo com Gomes (2016), o coordenador pedagógico é o profissional que torna realizável a incorporação e a articulação do trabalho pedagógico e está, de maneira direta, relacionado com a comunidade escolar que é composta pelos professores, pelos pais dos alunos e pelos alunos, com a finalidade de melhorar a qualidade do ensino. Assim, cabe-lhe

manter-se informado, para assim, corresponder às expectativas dos professores quanto à formação continuada, adotando uma postura de protagonista nesse processo; refletir sobre sua prática e a prática dos professores e sobre o currículo; atentar-se às mudanças em relação às políticas públicas no campo da educação, sejam em quaisquer das esferas governamentais; saber lidar com as exigências da sociedade da informação, com as exigências do aluno nativo digital e saber lidar com as tecnologias digitais; ter em mente a necessidade de aprender a aprender; adotar a postura de protagonista no processo de formação. (Ribeiro, 2016, p. 62)

Gomes (2016) comenta que esse relacionamento que o coordenador deve ter com os pais dos alunos e a comunidade escolar deve ser pautado no "funcionamento didático e curricular da escola, comunicação, e interpretação da avaliação dos alunos" (p. 17). Ao coordenador é conferida a tarefa de assistir os professores em sua didática. Criar situações que oportunizem a reflexão sobre a prática docente e contribuir para que novas oportunidades de aprendizagem sejam criadas, para que assim, possa auxiliar os alunos durante sua formação (Gomes, 2016).

O coordenador deve traçar meios para direcionar as ações pedagógicas, atuar de forma que consiga transformar o ambiente escolar em um espaço de formação em serviço dos professores, especialmente para os novos licenciados, que muitas vezes se frustram com a docência pela falta de experiência e de ação pedagógica de um coordenador competente (Oliveira; Guimarães, 2013).

Oliveira e Guimarães (2013) ressaltam que no contexto escolar, o coordenador pedagógico forma a parte essencial da articulação das ideias e recursos que atendem as necessidades dos alunos e professores, tendo em vista que este profissional deve articular a didática dos professores. Assim as pesquisadoras ressaltam que

o coordenador pedagógico no ambiente escolar constitui a articulação das ideias e recursos que atendam às necessidades dos professores e dos alunos, pois, é um profissional que articula as atividades pedagógicas em todo ambiente escolar para garantir a qualidade do ensino; que atua com a crítica em momento exato, ampliando o horizonte para a conquista de participação. (Oliveira; Guimarães, 2013, p. 97)

Assim, o coordenador pedagógico precisa tornar sua relação com os professores estável, para que ele possa ter a possibilidade de abordar publicamente e com liberdade os desafios que se surgem na escola. Tanto o coordenador como os professores devem ter a liberdade de o que desconhecem e juntos busquem soluções (Monteiro, 2012). 


\section{Considerações finais}

Portanto, de acordo com o que foi exposto acerca do papel do coordenador pedagógico, e levando em consideração a concepção dos teóricos citados acima, pode-se reconhecer a importância que o coordenador pedagógico tem no desenvolvimento dos processos escolares, na formação continuada dos professores e na aprendizagem dos alunos.

A coordenação pedagógica tem a responsabilidade de mobilizar os diferentes saberes dos profissionais que atuam na escola para levar os alunos ao aprendizado e contribuir para que essa aprendizagem seja capaz desenvolver competências e habilidades nos alunos, para que os mesmos possam ser transformados em cidadãos críticos e reflexivos.

Nesse contexto, esse profissional da educação é uma peça chave no processo educativo, especialmente no que tange à prática docente, pois uma das questões centrais que compete ao coordenador em sua prática é "trabalhar lado a lado com os professores a fim de que contribua no processo educativo, promovendo a reflexão da prática docente, assumindo um compromisso de junto ao professor trabalhar as dificuldades apresentadas no contexto escolar" (Farias; Farias; Silva; Magalhães, 2017, p. 2).

Por fim, vale ressaltar que a importância do coordenador para a escola está fundamentada no processo de reflexão que ele propicia a todos os que compõem a equipe pedagógica, sobretudo aos professores, já que o coordenador precisa levar os docentes a refletirem acerca de sua prática pedagógica e também nas diversas ocorrências que surgem no cotidiano escolar.

\section{Referências}

BARROS, Séfora; EUGÊNIO, Benedito G. O coordenador pedagógico na escola: formação, trabalho, dilemas. Educação, Gestão e Sociedade revista da Faculdade Eça de Queirós, v. 4, 2014, p. 1-15.

FERREIRA, Aurélio Buarque de Holanda. Miniaurélio século XXI: o minidicionário da língua portuguesa. Rio de Janeiro: Nova Fronteira, 2001.

FARIAS, Susanne Messias de; FARIAS, Carla Emanuele Messias de; SILVA, Chysomara Rowsy Tenório da; MAGALHAES, Elizângela Aureliano de. O papel do coordenador pedagógico no contexto da educação ambiental e suas contribuições para facilitar o trabalho na escola. ENCONTRO REGIONAL DE AGROECOLOGIA DO NORDESTE, 1, 2017. Maceió: Ufal, 2017.2 Disponível em <http://www.seer.ufal.br/index.php/era/article/view/3830/2916>. Acesso em 20 nov. 2018.

GOMES, Rita de Cássia. O papel do coordenador pedagógico na escola: uma análise das ações e práticas. 2016, 40f. Monografia (especialização em coordenação pedagógica). São Luís: UFMA 2016.2 Disponível em <https://monografias.ufma.br/jspui/handle/123456789/1916>. Acesso em 9 nov. 2018.

LEITE, Luciana Rodrigues de Freitas; MIRANDA, Rakel Sales; VERAS, kleyane Morais. Coordenador pedagógico na escola: influências da formação na prática profissional. Revista Ibero-Americana de de Educación, v. 73, n. 1, 2017, p. $29-49$.

BRASIL. Lei n. 9.394, 20 de dezembro de 1996. Estabelece as diretrizes e bases da educação nacional. Disponível em <http://www.planalto.gov.br/ccivil_03/leis/19394.htm>. Acesso em 23 nov. 2018. 
MONTEIRO, Elisabete. Coordenador pedagógico: função, rotina e prática. Palmeiras: Instituto Chapada de Educação e Pesquisa, 2012.

OLIVEIRA, Valdelici de. O papel do coordenador pedagógico na ordenação política da escola. Cuiabá: UFMT, 2010, 153f. Dissertação (mestrado em Educação). Universidade Federal de Mato Grosso. Instituto de Educação. Disponível em <http://livros01.livrosgratis.com.br/cp130506.pdf>. Acesso em 15 ago. 2018.

OLIVEIRA, Rejane Glória. O papel do coordenador pedagógico na mediação das novas tecnologias na prática pedagógica. Presidente Dutra: UFMA, 2016, 47f. Monografia (especialização em Coordenação pedagógica). Universidade Federal do Maranhão. Disponível em <https://monografias.ufma.br/jspui/handle/123456789/1915>. Acesso em 20 nov. 2018.

OLIVEIRA, Juscilene da Silva; GUIMARÃES, Márcia Campos Moraes. O papel do coordenador pedagógico no cotidiano escolar. Revista Científica do Centro de Ensino Superior Almeida Rodrigues, v. 1, n. 1, 2013, p. 95-103. Disponível em <http://www.faculdadefar.edu.br/revista/detalhe/id/1>. Acesso em 24 nov. 2018.

PINTO, Carlos Augusto Ribeiro. Patrimônio histórico, identidade cultural e turismo: o barroco mineiro. Brasília: UNB, 2006, 57f. Monografia (especialização em Formação de Professores e Pesquisadores em Turismo e Hospitalidade). Universidade de Brasília.

RIBEIRO, Raimunda Maria da Cunha. O coordenador pedagógico na escola pública: dilemas, contradições e desafios de um profissional iniciante. Revista Reflexão e Ação, Santa Cruz do Sul, v. 24, n. 2, 2016, p. 59-78. Disponível em: <https://online.unisc.br/seer/index.php/reflex/issue/view/328>. Acesso em: 26 nov. 2018.

SILVA, Ana Kátia da Costa. A formação continuada na coordenação pedagógica: a reflexão dos professores de uma escola da rede pública inseridos no âmbito do curso do Pacto Nacional pela Alfabetização na Idade Certa. Brasília: UNB, 2015, 47f. Monografia (especialização em coordenação pedagógica). Universidade de Brasília.

SILVA, Lenine Ferreira de. Professores alfabetizadores e coordenação pedagógica: um olhar diferente? Disponível em <http://educere.bruc.com.br/arquivo/pdf2015/19117_9038.pdf>. Acesso em 9 ago. 2018.

TEIXEIRA, Miriam Santana; AMORIM, Antonio; LOPES, Mariana Moraes; SOUZA, Amilton Alvez de. O coordenador pedagógico como articulador da formação de professores e de sua identidade profissional. Acta Scientiarum Educacion, v. 40, n. 3, 2018, p. 1-13.

Eliene Farias Silva é estudante na Universidade Estadual de Alagoas.

Orcid: https://orcid.org/0000-0001-8395-1079.

Endereço: Rua Governador Luís Cavalcante, s/n - Alto do Cruzeiro - 57312-000 -

Arapiraca - AL - Brasil.

E-mail: elienefarias@hotmail.com.

Recebido em 8 de fevereiro de 2019.

Aceito em 23 de abril de 2019.

(c) (1) 